\title{
Association between Prehospital Arterial Hypercapnia in Acute Heart Failure and Admission to Acute Care Units: a Retrospective Cohort Study
}

Mathias Fabre ( $\nabla$ mathias.fabre@hcuge.ch )

Hôpitaux Universitaires de Genève https://orcid.org/0000-0002-5676-6537

Christophe A FehImann

Hopitaux Universitaires de Geneve

Birgit Gartner

Hopitaux Universitaires de Geneve

Catherine G Zimmermann

Hopitaux Universitaires de Geneve

Florian Rey

Hopitaux Universitaires de Geneve

François Sarasin

Hopitaux Universitaires de Geneve

Laurent Suppan

Hopitaux Universitaires de Geneve

Original Research

Keywords: Acute Heart Failure, Hypercapnia, Prehospital, Intensive Care

Posted Date: May 26th, 2020

DOl: https://doi.org/10.21203/rs.3.rs-30079/v1

License: (9) (i) This work is licensed under a Creative Commons Attribution 4.0 International License.

Read Full License 


\section{Abstract \\ Background}

Acute Heart Failure (AHF) is a common condition that often manifests by acute respiratory distress and requires urgent medical evaluation and treatment. Arterial hypercapnia is common in AHF. It has been associated with a higher rate of intubation and non-invasive ventilation in the Emergency Room (ER), but its prognostic value has never been studied in the prehospital setting.

\section{Methods}

A retrospective study was performed on the charts of all patients taken care of by a physician-staffed prehospital mobile unit between June 2016 and September 2019 in Geneva. After approval by the ethics committee, charts were screened to identify all adult patients with a diagnosis of AHF. The main predictor was prehospital hypercapnia. The primary outcome was admission rate in an acute care unit (ACU, composite of intensive care or high-dependency units). Secondary outcomes were ER length of stay (LOS), orientation from ER (intensive care unit, high-dependency unit, general ward, discharge home), intubation rate at 24 hours, hospital LOS and hospital mortality.

\section{Results}

A total of 104 patients with a diagnosis of AHF were included. Hypercapnia was found in 59 (57\%) patients and vital signs were more severely altered in this group. The overall ACU admission rate was $47 \%$, with a statistically significant difference between hypercapnic and non-hypercapnic patients (58\% vs $33 \%$ respectively, $p=0.014$ ). ER LOS was shorter in hypercapnic patients ( 5.5 hours vs 8.9 hours, $p=$ $0.008)$.

\section{Conclusions}

There is a significant association between prehospital arterial hypercapnia and acute care unit admission in AHF patients.

\section{Background}

Acute Heart Failure (AHF) is a common but life-threatening condition with a high mortality. It often manifests by acute respiratory distress and requires urgent medical evaluation and treatment [1,2]. Classical treatment includes use of vasodilators, diuretics and oxygen, as well as positive end-expiratory pressure (PEEP), with or without pressure support (PS), for severe AHF [3-11]. In the prehospital setting, application of PEEP, whether by use of continuous positive airway pressure (CPAP) or of noninvasive ventilation (NIV), is associated with an improvement of vital parameters and a reduction in both 
endotracheal intubation (ETI) and intensive care unit (ICU) admission rates [12-16]. Common negative prognostic markers for AHF include hypotension on admission, advanced age and polymorbidity, as well as an ischemic etiology [2].

Arterial blood gas has been shown as a useful tool for prehospital physician [17]. Hypercapnia is commonly found in patients admitted to the ICU because of AHF $[18,19]$. The pathophysiological mechanisms leading to hypercapnia in this context are not fully understood. Muscle fatigue, which leads to hypoventilation, certainly contributes to the increase in $\mathrm{PaCO}_{2}$ [20]. It has also been theorized that gas exchange might be impaired by the development of interstitial edema [21]. Though Konishi et al. have shown that hypercapnia is associated with increased rates of both NIV and ETI in the intra-hospital setting [18], its predictive value in the prehospital environment is not known.

The goal of this study was to evaluate the association between prehospital hypercapnia and admission to acute care units (ACU), including ICU and high-dependency units (HDU).

\section{Methods}

\section{Study Design}

This is a retrospective cohort study, based on data obtained from charts review, exploring the association between hypercapnia in the prehospital field and admission to an ACU. It was approved by the institutional ethics committee of Geneva, Switzerland (project ID 2019 - 01559). Patient consent was waived by this committee.

\section{Setting}

This study was realized in the prehospital medical unit (called SMUR for Service Mobile d'Urgence et de Réanimation) of the Geneva University Hospitals in Switzerland, the detailed organization of which has previously been described [12]. Briefly, the prehospital emergency medical response in Geneva consists of three levels of increasing expertise (advanced life support ambulance, medical mobile unit, senior emergency-medicine certified physician). The SMUR is staffed by a paramedic and a resident and is called upon according to specific dispatch protocols or if the first responding paramedics request it. Severe respiratory distress is one of the criteria used to dispatch this unit. In addition to providing medical skills and knowledge, the SMUR can initiate NIV in the field well before arrival to the emergency room (ER). A Hamilton T1 ventilator (Hamilton Medical AG, Bonaduz, Switzerland) has been part of the standard SMUR equipment since 2013. Arterial blood gas (ABG) analysis has been possible since 2016 thanks to a portative i-STAT point-of-care blood analyzer device (Abbott Point of Care inc., Princeton, New Jersey, USA). The indication for drawing an ABG sample in the field is left to the physician's appreciation but is strongly suggested whenever NIV treatment is initiated. In order to avoid unnecessary delays, SMUR physicians are only allowed one single attempt on the radial artery in at most one minute.

\section{Participants}


The computerized charts of all adult patients for whom an intervention took place between 01.07.2016 and 30.09.2019 were screened for inclusion. Inclusion criteria were a primary diagnosis of "acute pulmonary edema" (APE) or "heart failure" (HF), which are coded according to a limited list of standardized prehospital diagnoses. These diagnoses were clinical, based on the evaluation by the prehospital physician. Charts were then manually reviewed to exclude patients in whom no acute component to the HF could be found. Other exclusion criteria were presence of a mixed or unclear diagnosis (such as a concomitant acute chronic obstructive pulmonary disease exacerbation), secondary transfer from another hospital or emergency structure, cardiac arrest upon rescuers' arrival, and care limitation defined as no ACU admission. Patients for whom prehospital arterial ABG could not be obtained (lack of sample, venous sample, technical problem, ABG not documented in chart) were finally excluded.

\section{Data Collection}

Validated, indexed data of all the patients included in the analysis was imported to a REDCap (Vanderbilt University, Nashville, Tennessee, USA) electronic case report form (CRF). The first author (MF) was in charge of the full data collection, including all the manual data extraction required to complete the CRF. Any doubt was lifted by a consensus between MF and two of the other authors (CAF and LS).

\section{Point-of-Care Analyzer}

The main predictor was prehospital hypercapnia, defined as PaCO2 of $6 \mathrm{kPa}(45 \mathrm{mmHg})$ and more. According to our institutional guidelines, the accuracy of the i-STAT analyzer was regularly assessed by internal and external quality controls (QC). Internal QC were tested at multiple levels on each lot number at delivery for precision evaluation. External QC were performed at least 7 times per year for accuracy evaluation. QC of the 'analyzer' itself was achieved by use of an electronic check cartridge twice per year for electronics evaluation.

\section{Outcomes}

The primary outcome was ACU admission, a composite outcome of admission to either HDU or ICU. Secondary outcomes were ER length of stay (LOS), orientation from ER (ICU, HDU, general and internal medicine wards, or discharge home), ETI (on field or in the first 24 hours), hospital LOS and hospital mortality.

Week-end interventions were those performed on Saturdays and Sundays. Night interventions occurred from 7PM to 7AM. Length of intervention was the time elapsed between the arrival on site and the arrival at hospital. In-hospital ABG was retained if made in the first hour in emergency. Others blood samples were retained if realized in first 6 hours in ER.

\section{Statistical Analysis}

As it was an exploratory study, no sample size calculation was realized. Groups were compared by Student's T-test, Mann-Whitney Wilcoxon test and chi-squared test as appropriate. Results are expressed 
as mean \pm standard deviation or absolute number and relative percentage. When appropriate, $95 \%$ confidence interval $(95 \mathrm{Cl})$ are also reported. A bilateral p-value below 0.05 was considered significant. A single subgroup analysis was performed according to whether there was a correction of hypercapnia at arrival in the ER. Missing data were reported as such and patients excluded from analyses if necessary (no imputation). Statistical analysis was performed using STATA version 14 (Stata Corporation, College Station, Texas, USA).

\section{Results}

A total of 17 '997 patients were taken care of by the SMUR during the study period. Among them, 972 met the inclusion criteria, as they had either a primary or a secondary diagnosis of APE or HF. We then excluded 868 patients to finally include 104 patients (10.7\%) in the analysis (Fig. 1). 139 patients were excluded from the study because they lacked prehospital ABG. Patients in whom ABG were available had a higher systolic blood pressure (182 versus $166 \mathrm{mmHg}, \mathrm{p}<0.001$ ), a higher respiratory rate (36 versus 32 per minute, $p<0.001$ ), a lower saturation ( $85 \%$ versus $88 \%, p<0.001)$ ), and seemed to be more likely to be admitted to an ACU ( $47 \%$ versus $35 \%, p=0.080)$.

Table 1 summarizes patients' characteristics. Most patients were women (55\%) and aged $79 \pm 8$ years. More than half of the patients (56.7\%) had hypercapnia on site with an average $\mathrm{PaCO}_{2}$ of $7.6 \pm 1.6$. Patients with and without hypercapnia were similar regarding personal history except for chronic hypertension and likely coronary heart disease and diabetes. However, prehospital vital signs as well as Glasgow coma scale (GCS) were more severely altered in the hypercapnia group. Hypercapnic patients were more often put under NIV, which was set at significantly higher PS settings. Hypercapnic patients who did not correct their $\mathrm{PaCO} 2$ upon ER arrival had similar baseline vital parameters and were not more likely to be admitted to an ACU than those who did correct their PaCO2 (respectively $69 \%$ versus $58 \%, p=$ 0.423).Data were missing mainly for GCS (18\%) and ER hypercapnia (19\%). 
Table 1

Patient's characteristics ${ }^{1}$

\begin{tabular}{|c|c|c|c|}
\hline & $\begin{array}{l}\text { No prehospital } \\
\text { hypercapnia } \\
(n=45)\end{array}$ & $\begin{array}{l}\text { Prehospital } \\
\text { Hypercapnia } \\
(n=59)\end{array}$ & $\begin{array}{l}\mathrm{p}- \\
\text { value }\end{array}$ \\
\hline Age (y) & $79.2 \pm 8.0$ & $79.5 \pm 8.0$ & 0.871 \\
\hline $\operatorname{Sex}(f)-n(\%)$ & $21(46.7)$ & $36(61.0)$ & 0.145 \\
\hline Week-end intervention - n (\%) & $16(36.4)$ & $13(22.4)$ & 0.122 \\
\hline Night intervention - n (\%) & $26(57.8)$ & $37(6271)$ & 0.610 \\
\hline Length of intervention (m) & $41 \pm 10$ & $42 \pm 11$ & 0.660 \\
\hline \multicolumn{4}{|l|}{ Personal history - n (\%) } \\
\hline Hypertension & $37(82.2)$ & $56(94.9)$ & 0.037 \\
\hline Coronary heart disease & $19(42.2)$ & $17(28.8)$ & 0.154 \\
\hline Atrial fibrillation & $22(48.9)$ & $22(37.3)$ & 0.235 \\
\hline Pacemaker & $11(24.4)$ & $9(15.3)$ & 0.239 \\
\hline Active cancer & $2(4.4)$ & $3(5.1)$ & 0.880 \\
\hline $\begin{array}{l}\text { Chronic obstructive pulmonary } \\
\text { disease }\end{array}$ & $8(17.8)$ & $9(15.3)$ & 0.730 \\
\hline Diabetes mellitus & $13(28.9)$ & $26(44.1)$ & 0.113 \\
\hline Chronic renal failure & $18(40.0)$ & $28(47.5)$ & 0.479 \\
\hline Prior hospitalisation for heart failure & $15(33.3)$ & $25(42.4)$ & 0.572 \\
\hline Tobacco & $7(15.6)$ & $9(15.3)$ & 0.976 \\
\hline \multicolumn{4}{|l|}{ Prehospital vital signs } \\
\hline Heart rate $(1 / \mathrm{min})$ & $104 \pm 20$ & $114 \pm 20$ & 0.018 \\
\hline Systolic blood pressure $(\mathrm{mmHg})$ & $174 \pm 31$ & $189 \pm 30$ & 0.018 \\
\hline Diastolic blood pressure $(\mathrm{mmHg})$ & $94 \pm 16$ & $112 \pm 18$ & $<0.001$ \\
\hline Respiratory rate $(1 / \mathrm{min})$ & $34 \pm 9$ & $38 \pm 7$ & 0.028 \\
\hline Oxygen saturation (\%) & $86 \pm 9$ & $83 \pm 12$ & 0.269 \\
\hline
\end{tabular}

${ }^{1}$ Plus - minus values are means \pm SD, Percentages may not total 100 due to rounding. PEEP: Positive End-Expiratory Pressure. PS: Pressure Support 


\begin{tabular}{|c|c|c|c|}
\hline & $\begin{array}{l}\text { No prehospital } \\
\text { hypercapnia } \\
(n=45)\end{array}$ & $\begin{array}{l}\text { Prehospital } \\
\text { Hypercapnia } \\
(n=59)\end{array}$ & $\begin{array}{l}\mathrm{p}- \\
\text { value }\end{array}$ \\
\hline Glasgow Coma Scale - n (\%) & $3(6.7)$ & $17(28.8)$ & 0.017 \\
\hline$<15$ & 33 (73.3) & $32(54.2)$ & \\
\hline 15 & $9(20.0)$ & $10(17.0)$ & \\
\hline \multicolumn{4}{|l|}{ Missing values } \\
\hline Prehospital $\mathrm{PaCO}_{2}(\mathrm{kPa})$ & $5.0 \pm 0.6$ & $7.6 \pm 1.6$ & $\begin{array}{l}< \\
0.001\end{array}$ \\
\hline Prehospital pH & $7.38 \pm 0.06$ & $7.23 \pm 0.11$ & $\begin{array}{l}< \\
0.001\end{array}$ \\
\hline Prehospital NIV & $34(75.6)$ & $57(96.6)$ & 0.001 \\
\hline $\operatorname{PEEP}(\mathrm{mmHg})$ & $6.0 \pm 1.7$ & $6.4 \pm 2.0$ & 0.382 \\
\hline$P S$ & $8.1 \pm 1.7$ & $9.4 \pm 2.2$ & 0.006 \\
\hline Hospital hypercapnia - n (\%) & & & 0.001 \\
\hline No hypercapnia & $29(64.4)$ & $24(40.7)$ & \\
\hline Hypercapnia & $5(11.1)$ & $26(44.1)$ & \\
\hline Missing value & $11(24.4)$ & $9(15.3)$ & \\
\hline \multicolumn{4}{|l|}{ Emergency room work-up } \\
\hline Haemoglobin $(g / d l)$ & $130 \pm 23$ & $125 \pm 20$ & 0.213 \\
\hline Serum creatinine $(\mu \mathrm{mol} / \mathrm{l})$ & $128 \pm 75$ & $153 \pm 150$ & 0.275 \\
\hline Pro-B-type natriuretic peptide ( $(\mathrm{gg} / \mathrm{l})$ & $6225 \pm 7548$ & $6548 \pm 9679$ & 0.870 \\
\hline
\end{tabular}

The global ACU admission rate was $47 \%$ (49/104), with a statistically and clinically significant difference between patients with and without hypercapnia $(57.6 \%$ vs $33.3 \%, p=0.014)$ (Table 2). This difference was likely due to a higher admission rate in ICU for hypercapnic patients (32.2\% versus $8.9 \%$ ).

Hypercapnic patients who did not correct their $\mathrm{PaCO}_{2}$ upon ER arrival were not more likely to be admitted to an ACU than those who did correct their $\mathrm{PaCO}_{2}$ (respectively $69 \%$ versus $58 \%, p=0.423$ ). The change in $\mathrm{PaCO}_{2}$ in hypercapnic patients between prehospital and ER ABG was not associated with ACU admission either (respectively $-1.20 \mathrm{kPa}$ for patients admitted to an ACU versus $-1.13 \mathrm{kPa}$ for those who were not, $p=0.848)$. 
Table 2

Outcomes $^{2}$

\begin{tabular}{|c|c|c|c|c|}
\hline & $\begin{array}{l}\text { All } \\
(n= \\
104)\end{array}$ & $\begin{array}{l}\text { No prehospital } \\
\text { hypercapnia } \\
(n=45)\end{array}$ & $\begin{array}{l}\text { Prehospital } \\
\text { Hypercapnia } \\
(n=59)\end{array}$ & $\begin{array}{l}\text { p- } \\
\text { value }\end{array}$ \\
\hline \multicolumn{5}{|l|}{ Primary outcome } \\
\hline ACU admission - n (\%) & $\begin{array}{l}49 \\
(47.1)\end{array}$ & $15(33.3)$ & $34(57.6)$ & 0.014 \\
\hline \multicolumn{5}{|l|}{ Secondary outcomes } \\
\hline Emergency LOS (h) & $7.0 \pm 6.5$ & $8.9 \pm 9.0$ & $5.5 \pm 3.0$ & 0.008 \\
\hline $\begin{array}{l}\text { Orientation from ER - n } \\
(\%)\end{array}$ & & & & 0.005 \\
\hline ICU admission & $\begin{array}{l}23 \\
(22.1)\end{array}$ & $4(8.9)$ & $19(32.2)$ & \\
\hline HDU admission & $\begin{array}{l}26 \\
(25.0)\end{array}$ & $11(24.4)$ & $15(25.4)$ & \\
\hline Ward & $\begin{array}{l}51 \\
(49.0)\end{array}$ & $26(57.8)$ & $25(42.4)$ & \\
\hline $\begin{array}{l}\text { Discharge directly from } \\
E R\end{array}$ & $4(3.9)$ & $4(8.9)$ & $0(0.0)$ & \\
\hline ETI - n (\%) & $5(4.8)$ & $0(0.0)$ & $5(8.5)$ & 0.045 \\
\hline Hospital LOS (d) & $\begin{array}{l}13.2 \pm \\
9.4\end{array}$ & $11.9 \pm 6.8$ & $14.2 \pm 10.9$ & 0.229 \\
\hline $\begin{array}{l}\text { Hospital mortality - n } \\
(\%)\end{array}$ & $5(4.8)$ & $1(2.2)$ & $4(6.8)$ & 0.282 \\
\hline
\end{tabular}

\section{Discussion}

Our study shows a significant association between prehospital hypercapnia and ACU admission. This result seems mainly explained by the difference in ICU admissions between the two groups.

The difference between hypercapnic and non-hypercapnic patients regarding ACU admissions is probably best explained by the fact that hypercapnic patients seemed to be in a worse clinical state. These patients were indeed more tachycardic, more severely hypertensive, had lower GCS scores and higher respiratory rates. They also had a higher ETI rate at 24 hours. The association between hypercapnia and 
worse clinical state is not fully understood, but could be linked to respiratory muscle fatigue or impaired gas exchange due to interstitial edema $[19,20]$.

Hypercapnia was associated with a significantly lower LOS in the ER. Though it can hardly be assumed that hypercapnia alone was responsible for this time reduction in ER, one might argue that in-hospital orientation for patients with worse clinical state was more straightforward and could therefore account for this finding. Whether the ER physicians took prehospital ABG results into account could not be ascertained owing to the design of this study.

Other limitations must also be acknowledged. The small study sample did not have sufficient power to draw conclusions regarding mortality or to adjust our results for potential confounders. This lack of power is, among other things, due to lack of ABG samples. As described above, patients in whom ABG were lacking were in a better clinical state. Although this is probably the result of the prehospital physicians' choice to avoid drawing arterial blood in patients who clearly did not need NIV, it could nevertheless have resulted in an important selection bias. Other valuable data, such as usual medications, frailty parameters, or left ventricular function could not be obtained, further limiting the interpretation of our findings. Moreover, though a clear relationship between ACU admission and prehospital hypercapnia has been found, such a relationship does not necessarily imply causality. One last limitation is the retrospective design of this study, as diagnosis of heart failure can differ from one physician to another. Nevertheless, as our prehospital chart only allows the use of a limited and standardized list of diagnoses, such differences might have been mitigated.

Despite these elements, it is fair to note the good quality of patient's data, due to chart review, thus limiting memorization bias. Another strong point is that, as prehospital hypercapnia has to our knowledge never been studied in AHF, this work shows new elements that could improve patient orientation in the ER. Prospective studies would be needed to better describe the role of prehospital hypercapnia in AHF.

\section{Conclusion}

In conclusion, this study shows a significant association between prehospital arterial hypercapnia, ACU admissions, ER LOS and ETI in patients with AHF. Prospective studies need however confirm these results before prehospital $A B G$ can be recommended on a routine basis.

\section{Abbreviations}

ABG Arterial Blood Gas

ACU Acute Care Unit

AHF Acute Heart Failure

APE Acute pulmonary Edema 
CRF Case Report Form

CPAP Continuous Positive Airway Pressure

ER Emergency Room

ETI Endotracheal Intubation

GCS Glasgow Coma Scale

HDU High-dependency Unit

HF Heart Failure

ICU Intensive Care Unit

LOS Length of Stay

NIV Non-Invasive Ventilation

PEEP Positive End-Expiratory Pressure

PS Pressure Support

QC Quality Control

SMUR Service Mobile d'Urgences et de Réanimation

\section{Declarations}

\section{Ethics approval and consent to participate:}

The study was conducted at Geneva University Hospitals in accordance with Good Clinical Practice (Declaration of Helsinki 2002). This study was approved on 20.08 .2019 by the institutional ethics committee of Geneva, Switzerland (Project ID 2019 - 01559). Patient consent was waived by this committee.

\section{Consent for publication:}

Not applicable

\section{Availability of data and material:}


The datasets used and analysed during the current study are available from the corresponding author on reasonable request.

\section{Competing interests:}

The authors declare no competing interests

\section{Funding:}

This research receive no external funding

\section{Authors Contributions:}

conceptualization, M.F., C.A.F, B.G., F.S., L.S.; formal analysis, C.A.F and L.S.; investigation, M.F.; data curation: C.A.F.; writing-original draft, M.F., C.A.F.; writing-review and editing, M.F., C.A.F., B.G., C.Z.I, F.R., F.S., L.S.; supervision: F.S., L.S.; Project administration, L.S. All authors have read and agreed to the submitted version of the manuscript.

\section{Acknowledgements :}

not applicable

\section{References}

1. Ponikowski P, Voors A, Anker S, Bueno H, Cleland J. Coats A, Falk V, et al. 2016 ESC Guidelines for the Diagnosis and Treatment of Acute and Chronic Heart Failure. Eur Soc Cardiol. 2016;37:2129-200. doi:10.1016/j.rec.2016.10.015.

2. Tubaro M, Price S, Vrints C. Acute Heart Failure: Epidemiology, classification and pathophysiology. In: ESC Textbook of Intensive and Acute Cardiovascular Care. 2014. doi:10.1016/s1261-694x(14)706790 .

3. Potts JM. Noninvasive positive pressure ventilation - Effect on mortality in acute cardiogenic pulmonary edema: A pragmatic meta-analysis. Pol Arch Med Wewn. 2009;119(6):349-53.

4. Cabrini L, Landoni G, Oriani A, Plumari VP, Nobile L, Greco M, et al. Noninvasive ventilation and survival in acute care settings: A comprehensive systematic review and metaanalysis of randomized controlled trials. Crit Care Med. 2015;43(4):880-8. doi:10.1097/CCM.0000000000000819.

5. Masip J, Roque M. Noninvasive Ventilation in Acute Cardiogenic Pulmonary Edema: Systematic review and meta-analysis. J Am Med Assoc. 2005;294(24). doi:10.1001/jama.294.24.3124. 
6. Mariani J, MacChia A, Belziti C, Deabreu M, Gagliardi J, Doval H, et al. Noninvasive ventilation in acute cardiogenic pulmonary edema: A meta-analysis of randomized controlled trials. J Card Fail. 2011;17(10):850-9. doi:10.1016/j.cardfail.2011.05.010.

7. Vital F, Ladeira M, Atallah A. Non-invasive positive pressure ventilation (CPAP or bilevel NPPV) for cardiogenic pulmonary oedema (Review ). Cochrane database Syst Rev. 2013;(5). doi:10.1002/14651858.CD005351.pub3.www.cochranelibrary.com.

8. Berbenetz N, Wang Y, Brown J, Vital FMR. Non-invasive positive pressure ventilation (CPAP or bilevel NPPV) for cardiogenic pulmonary oedema. Cochrane database Syst Rev. 2019;5(5):CD005351. doi:10.1002/14651858.CD005351.pub3.

9. Weng C-L, Zhao Y-T, Liu Q-H, Fu C-S, Sun F, Ma. Y-L, et al. Meta-analysis. Noninvasive Ventilation in Acute Cardiogenic Pulmonary Edema. Ann Intern Med. 2010;152(9):590. doi:10.7326/0003-4819152-9-201005040-00009.

10. Gray A, Goodacre S, Newby DE, Masson M, Sampson F, Nicholl J. Noninvasive Ventilation in Acute Cardiogenic Pulmonary Edema. N Engl J Med. 2008;359(2):142-51. doi:10.1056/NEJMoa0707992.

11. Mosesso VN, Dunford J, Blackwell T, Griswell JK. Prehospital therapy for acute congestive heart failure: State of the art. Prehospital Emergency Care. 2003. doi:10.1080/10903120390937049.

12. Gartner BA, Fehlmann C, Suppan L, Niquille M, Rutschmann OT, Sarasin F. Effect of noninvasive ventilation on intubation risk in prehospital patients with acute cardiogenic pulmonary edema: a retrospective study. Eur J Emerg Med. July 2019. doi:10.1097/MEJ.0000000000000616.

13. Weitz G, Struck J, Zonak A, Balnus S, Perras B, Dodt C. Prehospital noninvasive pressure support ventilation for acute cardiogenic pulmonary edema. Eur J Emerg Med. 2007;14(5):276-9. doi:10.1097/MEJ.0b013e32826fb377.

14. Simpson PM, Bendall JC. Prehospital non-invasive ventilation for acute cardiogenic pulmonary oedema: An evidence-based review. Emerg Med J. 2011;28(7):609-12. doi:10.1136/emj.2010.092296.

15. Williams TA, Finn J, Perkins GD, Jacobs IG. Prehospital continuous positive airway pressure for acute respiratory failure: A systematic review and meta-analysis. Prehospital Emerg Care. 2013. doi:10.3109/10903127.2012.749967.

16. Taylor DMD, Bernard SA, Masci K, MacBean CE, Kennedy MP. Prehospital noninvasive ventilation: A viable treatment option in the urban setting. Prehospital Emerg Care. 2008. doi:10.1080/10903120701710389.

17. Zwisler ST, Zincuk Y, Bering CB, Zincuk A, Nybo M, Mikkelsen S. Diagnostic value of prehospital arterial blood gas measurements - A randomised controlled trial. Scand J Trauma Resusc Emerg Med. 2019. doi:10.1186/s13049-019-0612-8.

18. Konishi M, Akiyama E, Suzuki H, Iwahashi N, Maejima N, Tsukahara K, et al. Hypercapnia in patients with acute heart failure. ESC Hear Fail. 2015;2(1):12-9. doi:10.1002/ehf2.12023.

19. Lazzeri C, Gensini GF, Picariello C, Attanà P, Mattesini A, Chiostri M, et al. Acidemia in severe acute cardiogenic pulmonary edema treated with noninvasive pressure support ventilation: A single-center 
experience. J Cardiovasc Med. 2015;16(9):610-5. doi:10.2459/JCM.0000000000000079.

20. Valipour A, Cozzarini W, Burghuber OC. Non-invasive pressure support ventilation in patients with respiratory failure due to severe acute cardiogenic pulmonary edema. Respiration. 2004. doi:10.1159/000076675.

21. Schlosshan D, Elliott M. Prognostic indicators in patients presenting with acute cardiogenic pulmonary edema treated with CPAP: It's not the acid that matters, it's back to basics. Crit Care. 2010;14(6):14-5. doi:10.1186/cc9325.

\section{Figures}

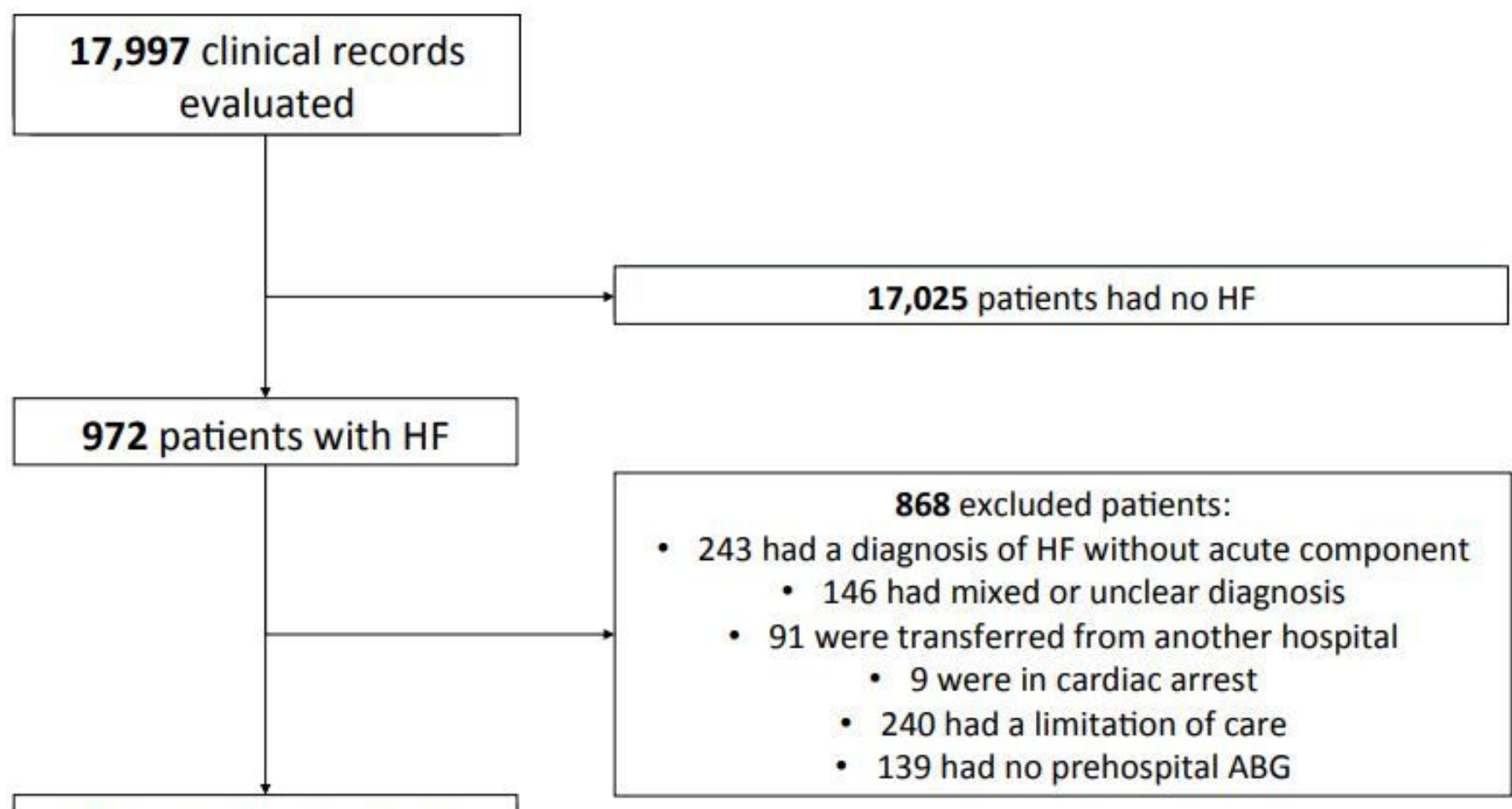

104 patients analyzed

\section{Figure 1}

Study Flowchart 